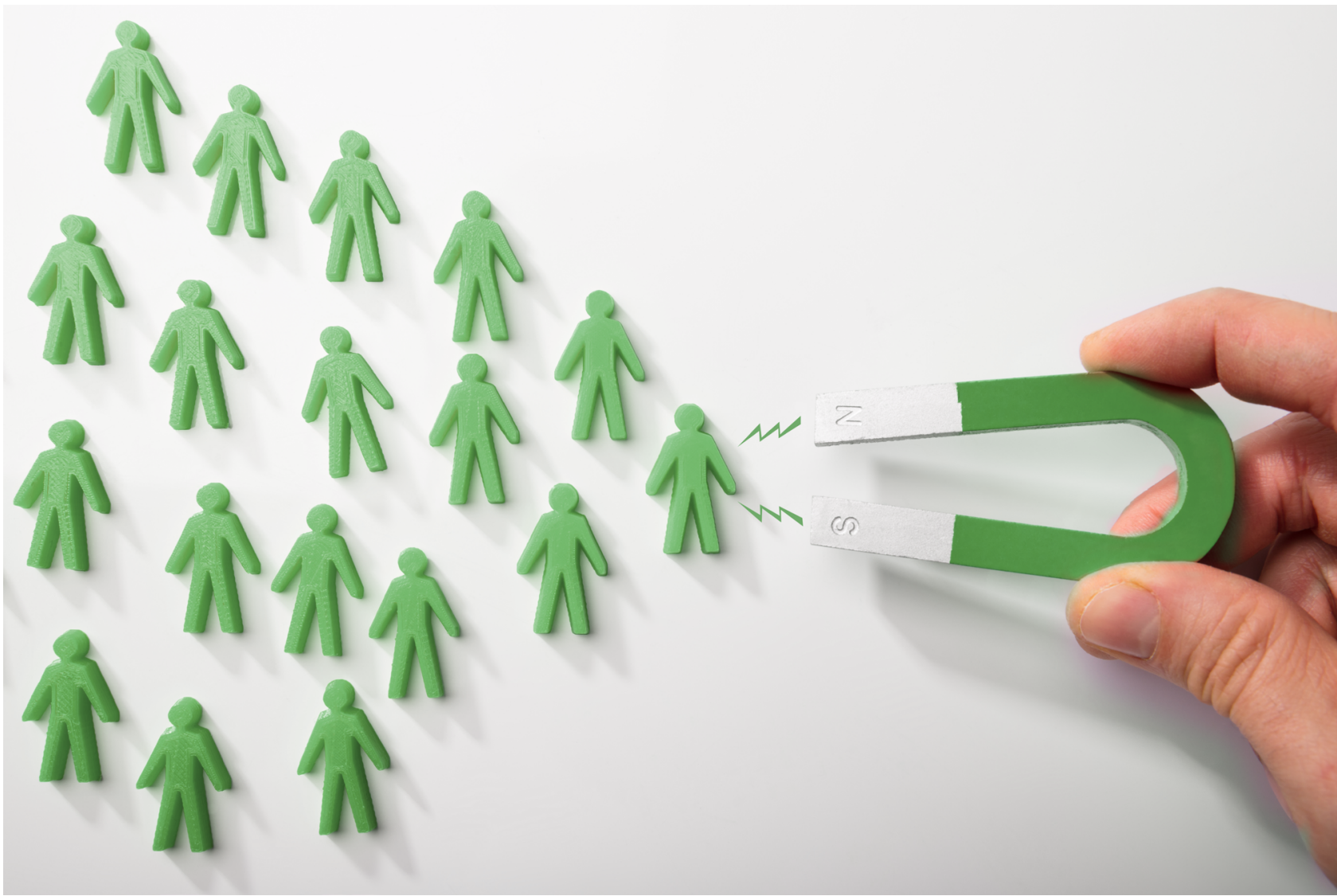

\title{
DE VOLTA PARA CASA
}

| POR LUIZ MIGLIORA NETO E MARCELLO ROMANI-DIAS

\section{POR QUE ESTAMOS PERDENDO E COMO PODEMOS REPATRIAR NOSSOS PROFESSORES EM ADMINISTRAÇÃO?}

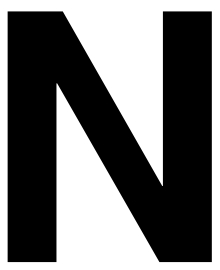

os últimos anos, um número cada vez maior de professores brasileiros têm deixado o país em busca de oportunidades no exterior, principalmente em países desenvolvidos. Se, por um lado, esse êxodo parece indicar que a qualificação de nossos acadêmicos tem evoluído em nível internacional, por outro essas que são algumas de nossas melhores "cabeças", em muitos casos, deixam de investir seu intelecto no Brasil.

\section{O QUE MOTIVA A SAÍDA?}

Em estudo sobre o tema, entrevistamos professores pesquisadores renomados, atuantes em algumas das principais escolas de negócios do Brasil. Com as conversas, notamos que há diversas razões que levam alguns de nossos melhores professores a saírem do Brasil para fazerem carreira internacionalmente.

Como primeira e principal motivação, aparece a busca por (i) melhores oportunidades de trabalho. Os Estados Unidos, 


\section{BUSCA POR OPORTUNIDADES DE TRABALHO, ESPERANÇA POR MELHOR QUALIDADE DE VIDA, DESENVOLVIMENTO PROFISSIONAL E AMPLIAÇÃO DA REDE DE CONTATOS ESTÂOO ENTRE OS PRINCIPAIS MOTIVADORES DA SAIIDA DE PROFESSORES DO BRASIL.}

por exemplo, possuem $28 \%$ do investimento global com pesquisa e desenvolvimento (P\&D), concentram $16,7 \%$ do total de pesquisadores do mundo e um quarto $(25 \%)$ do total de publicações mundiais. O país é frequentemente procurado por nossos professores por pagar salários médios maiores do que o Brasil para a carreira docente.

Outra motivação é a demanda por (ii) melhor qualidade de vida. A recessão no Brasil causou desemprego, agravando problemas de segurança, saúde e educação, e piorou ainda mais a distribuição de renda.

$\mathrm{O}$ (iii) desenvolvimento profissional é outro fator. Ao conhecer novas culturas, o professor tem a possibilidade de desenvolver sua capacidade de análise sistêmica, competência cada vez mais requerida em nosso contexto global.

A ampliação da rede de contatos (iv) é outro grande catalisador do êxodo de nossos professores. "Para construir uma rede acadêmica realmente forte, é necessário que você viaje", afirmou um dos professores com quem conversamos. Em âmbito de pesquisa, o mesmo professor afirmou que "quem tem rede internacional consegue ter um volume muito maior de publicações acadêmicas".

\section{A INTERNACIONALIZAÇÃO PENDULAR}

Uma alternativa para trazermos de volta nossos cérebros é a internacionalização pendular. Significa que o professor sai de seu país para exercer atividades profissionais, mas também retorna com frequência ao país de origem, estando fisicamente presente ou não. Esse tipo de mobilidade condiz com a lógica da carreira acadêmica e tem se tornado cada vez mais comum entre nossos professores de escolas de negócios.

É cada vez mais comum, por exemplo, lidarmos com professores que passam parte do ano no Brasil e parte do ano fora. Esses docentes muitas vezes voltam para sua terra natal com trabalhos específicos e temporários em mente, como o de ministrar um curso de férias ou uma disciplina trimestral. Outros, por sua vez, possuem contratos individuais com a instituição de ensino em que atuam e podem, por exemplo, acordar que exercerão suas atividades na instituição durante somente um semestre letivo, ou, ainda, em uma disciplina a distância (de forma remota).

Quando há mobilidade pendular, o capital intelectual do professor retorna ao Brasil e de forma renovada, por conta das suas experiências recentes no exterior. Como consequência, a nação consegue aproveitar de alguma forma as competências dessa mão de obra qualificada.

\section{O PAPEL DA EDUCAÇÃO EXECUTIVA E CORPORATIVA}

Os cursos de educação executiva e corporativa também podem ser uma inteligente alternativa para reduzirmos a perda de nossos talentos e repatriá-los. Para isso, em primeiro lugar, é necessária a retomada do crescimento econômico, que impulsiona a demanda por educação executiva e corporativa, pelo simples fato de as organizações precisarem reestruturar suas equipes.

Destacamos, além disso, que há três principais razões que fortalecem os cursos de educação executiva e corporativa como drivers de atração de professores expatriados:

\section{DEMANDA POR PROFESSORES COM EXPERIÊNCIA INTERNACIONAL}

Tomando como exemplo a educação corporativa da FGV EAESP, verifica-se a tendência de customização de programas de educação executiva, requerendo uma atuação próxima do professor com a organização. Assim, há demanda por serviços de professores com experiência internacional, especialmente pelas suas habilidades práticas globalizadas, o que é de fundamental importância para o treinamento dos colaboradores que deverão ser contratados pelas organizações e para a uniformização das equipes.

Além disso, professores têm plenas condições de combinar as suas atividades de pesquisa com educação executiva e corporativa, com os benefícios de maximizar seus ganhos financeiros e adquirir mais conhecimento prático. 


\section{PODEMOS TRAZER NOSSOS PROFESSORES DE ADMINISTRAÇ̃̃O DE VOLTA AO BRASIL COM A INTERNACIONALIZAÇÃO PENDULAR. OU SEJA, ELES RETORNAM FREQUENTEMENTE AO PAÍS E COM O FORTALECIMENTO DA EDUCAÇÃO EXECUTIVA E CORPORATIVA.}

As organizações requerem dedicação e tempo para que as atividades sejam customizadas. Portanto, essa é uma oportunidade de unir teoria e prática.

As constantes atualizações dos programas de educação executiva requerem conteúdos modernos, oriundos de pesquisas, realizadas pelos centros de estudos e de pesquisa das escolas, o que demanda mentes brilhantes.

\section{TECNOLOGIAS PARA MINIMIZAR}

\section{A MOBILIDADE FÍSICA DO PROFESSOR}

O professor que já tem histórico em educação executiva e corporativa pode atuar em uma instituição estrangeira e, ao mesmo tempo, ministrar uma aula remota para alunos do Brasil. A tecnologia atualmente permite aulas síncronas a distância, com o compartilhamento simultâneo de telas entre todos os participantes, simulando, portanto, um ambiente presencial de sala de aula.

Essas tecnologias são particularmente importantes para driblarmos os problemas de dificuldade de mobilidade física tanto por parte de professores como também dos alunos. Acreditamos que as modalidades de ensino a distância sejam uma tendência no futuro. Programas blended já estão sendo montados com aulas presenciais e aulas síncronas a distância.

Entretanto, essas tecnologias exigem mais maturidade do aluno, atuando como protagonista, idealmente no modelo de aula invertida, em que o tempo da aula a distância é utilizado para o debate entre os alunos executivos, mediado pelo professor, o que requer leituras prévias.

\section{TENDÊNCIAS SOBRE O MERCADO DE TRABALHO}

Pesquisa do Fórum Econômico Mundial trouxe importantes tendências sobre a demanda por competências globais para o período 2015-2020. Os trabalhadores do futuro terão de possuir, principalmente, habilidades em:

- resolução de problemas complexos;

- trato com pessoas e com a sociedade em geral;
- processos;

- sistemas.

As tendências apontadas vão ao encontro do que é oferecido pelos melhores cursos de educação executiva e corporativa, trazendo, portanto, uma visão otimista sobre o crescimento desses cursos nos próximos anos.

Também é possível traçarmos uma relação com uma expectativa de demanda crescente por professores internacionalizados, especialmente aqueles com experiência prática em negócios oriundos de outros países. Parte-se do pressuposto de que a experiência no exterior auxilia o professor na compreensão de diferentes culturas, e, assim, esse profissional desenvolve suas habilidades de lidar com pessoas e com problemas complexos. Associado a isso, também está o fato de vivenciar processos produtivos em diferentes países, aumentando seu acúmulo de conhecimento sobre processos e sistemas internacionais.

A pesquisa do Fórum Mundial ainda aponta que $65 \%$ das empresas precisarão treinar sua mão de obra no período 2015-2020 para readequação às tendências globais, o que nos traz a projeção de crescimento de demanda por cursos executivos e corporativos e, consequentemente, por professores.
PARA SABER MAIS:

World Economic Forum. The future of jobs: employment, skills and workforce strategy for the fourth industrial revolution, 2016.

Marcello Romani-Dias, Rodrigo Assunção Rosa, Aline dos Santos Barbosa, Rubens Mussolin Massa, Raissa Barbosa e Rubens Bonon-Filho. Internacionalizar é preciso? Motivadores, barreiras e facilitadores da internacionalização de pesquisadores em Administração Anais do XL EnANPAD, 2016

Manolita Correia Lima e Fábio Betioli Contel. Internacionalização da educação superior nações ativas, nações passivas e a geopolítica do conhecimento, 2011.

Ana Carolina Neira e Ricardo Rossetto. Com a crise, número de brasileiros que deixam o país quase dobra, O Estado de S. Paulo, 2017.

Unesco. Relato de Ciência da Unesco Rumo a 2030: visão geral e cenário brasileiro, 2015.

LUIZ MIGLIORA NETO > Doutorando no Doctorate on Business Administration (DBA) da FGV EAESP e diretor executivo do FGV In Company e da Rede

Conveniada FGV > luiz.migliora.neto@fgv.br

MARCELLO ROMANI-DIAS > Professor do Programa de Pós-Graduação em Administração da Universidade Positivo, professor da Escola Superior de

Engenharia e Gestão (ESEG) e da Fundação Instituto de Administração (FIA), doutor em Administração de Empresas pela FGV EAESP, com estágio doutoral no Instituto de Tecnologia de Massachusetts (MIT) > marcello.romani@up.edu.br 